\title{
Evaluation of the causes of prescription deductibles in a teaching hospital in Kermanshah
}

\author{
Behnam Reza Makhsosi ${ }^{1}$, Hossein Amiri ${ }^{2}$, Nasim Evani ${ }^{2 *}$, Sharmin Rahmani ${ }^{2}$, Soheila Kazazi ${ }^{2}$ \\ 1. Asadabad School of Medical Sciences, Asadabad, Iran \\ 2. Clinical Research Development Center, Imam Khomeini Hospital, Kermanshah University of Medical Sciences, \\ Kermanshah, Iran
}

Received: 1 December 2020

Accepted for publication: 7 August 2021

[EPub a head of print-15 August 2021]

Payesh: 2021; 20 (4): 415- 425

\begin{abstract}
Objectives: Due to the fact that most of insurance companies have deductions and long delays in the reimbursement of bills. They are causing dissatisfaction in the hospitals of the contracting party. Therefore, the present study was conducted with the aim of determining the causes of prescription deductibles in a teaching hospital in Kermanshah, Iran in 2018.

Methods: In this cross-sectional and descriptive-analytical study, all 560 cases related to 2018 year that were covered by the insurance of the hospital were examined. Data were analyzed using the SPSS software version 23. The significant level was set at 5 percent.

Results: The results of the present study showed that the mean and standard deviation of prescription deductibles in the hospital during 2019 were 16596782.90 and 335966366.43 Rails, respectively. The highest amount of prescription deductibles was recorded in January and the lowest was recorded in March. The highest cause of prescription deductibles in the opinion of the participants with a frequency of $44.4 \%$ was related to the lack of accurate and precise registration of drugs and equipment in the doctor's and nursing notes.

Conclusion: The findings suggest review of medication application forms by at least two people, reminding and educating doctors, inspection by insurance and income personnel regularly, encouraging staff if deductions are reduced, reducing the time interval between shifts of physicians and nurses, increasing cooperation between insurance companies and income personnel with the pharmacy department, and using specialists to update the price of medicines before entering the pharmacy might help to lessen prescription deductibles
\end{abstract}

Key words: Hospital, Drug Deductions, Insurance

\footnotetext{
* Corresponding author: Imam Khomeini Hospital, Kermanshah University of Medical Sciences, Kermanshah, Iran

E-mail: evani.nasim@gmail.com
} 


\section{بررسى ميزان و علل كسورات دارويى در يك بيمار ستان دانشكاهى در كر مانشاه}

\section{بهنام رضا مخصوصى'، حسين اميرى'، نسيم ايوانى '، شرمين رحمانى '، سهيلا كزازى'}

1. انشكده علوم يزشكى اسدآباد، اسدآباد، ايران

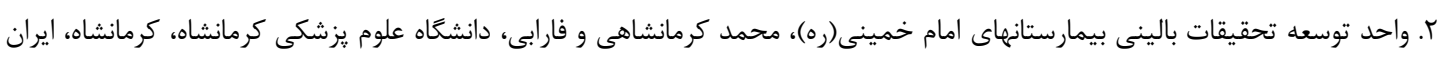

مقدمه: با توجه به اينكه اغلب سازمانهاى بيمهَ در در بازيرداخت بهاى صورتحسابها با اعمال كسـورات و تـأخير زيـاد همـراه هسـتند، موجـب نارضـايتى

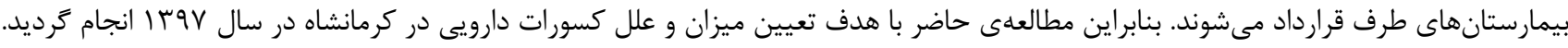

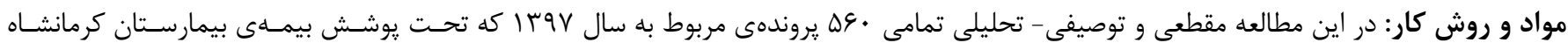

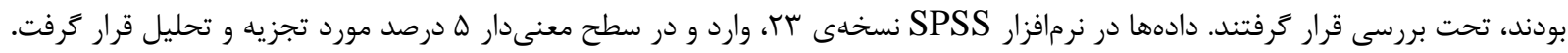

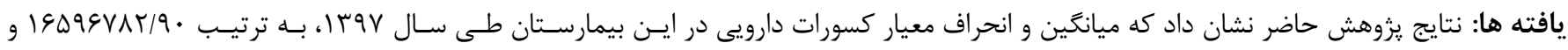

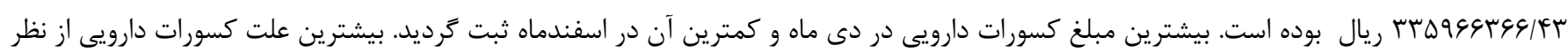

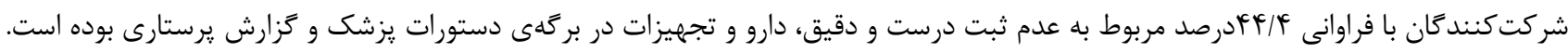

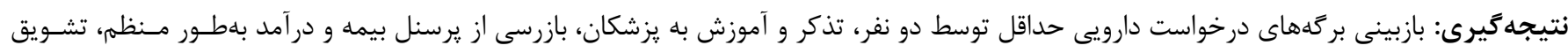

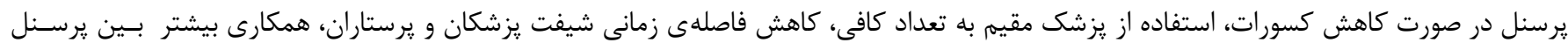

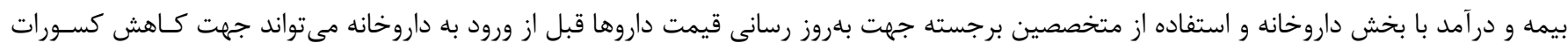

راه كشا باشد.

كليدوازه: بيمارستان، كسورات دارويى، بيمه

كداخلاق: IR.KUMS.REC.1397.961 
و همكاران در سال • • · انجام گرديد، مهـمتـرين علـل كسـورات، مستندسازى ناقص يرونده، ناآشنايى با سيستم اطلاعات بيمارستان،

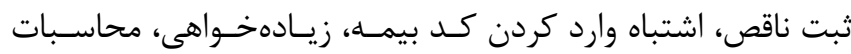

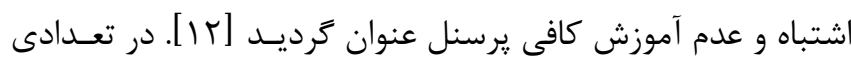

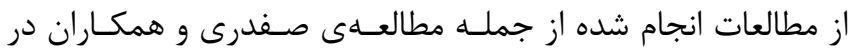

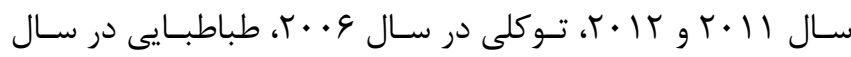

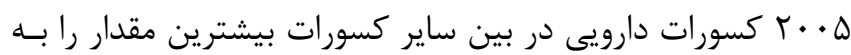

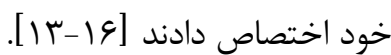

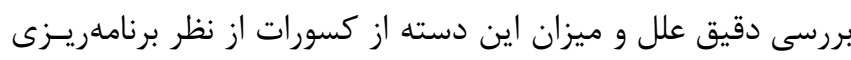

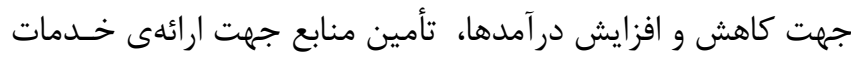

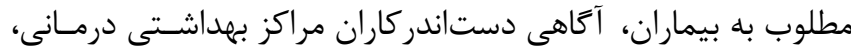

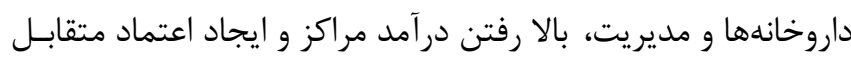

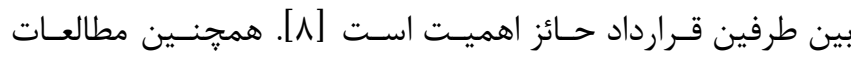

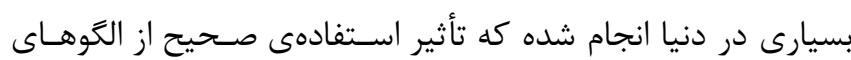

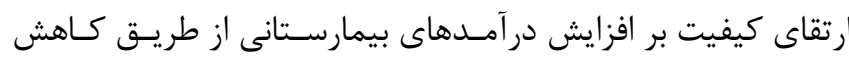

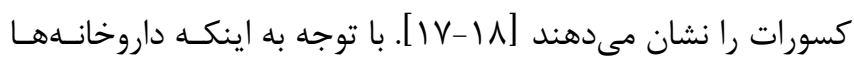

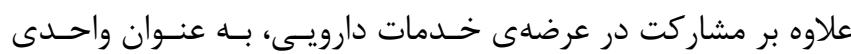

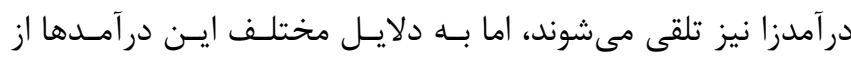

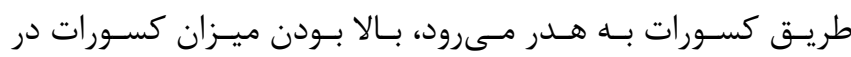

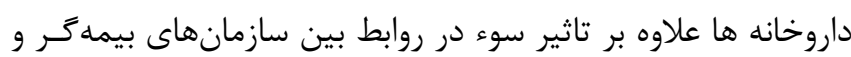

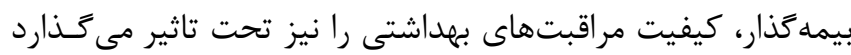

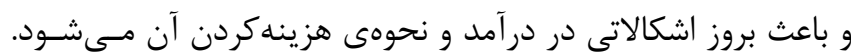

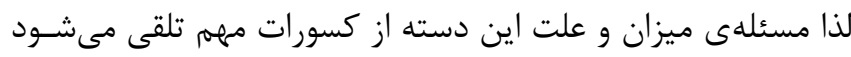

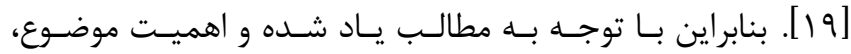

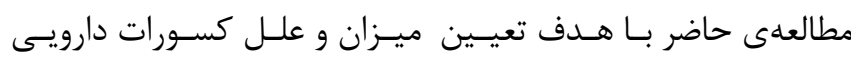

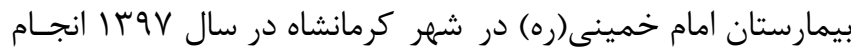

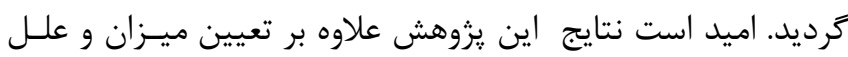

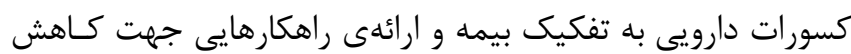

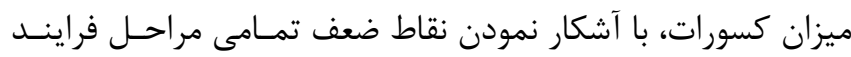

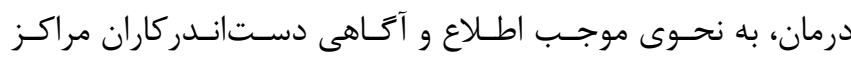

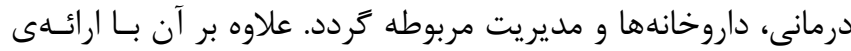

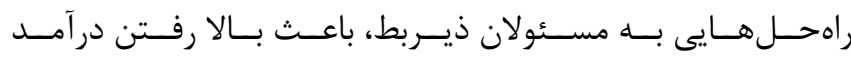
بيمارستانهاى تابعه و ايجاد يك اعتماد بين طرفين قرارداد شود.

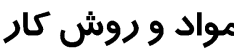

يزوهش حاضر، از نوع مقطعى و توصيفى - تحليلى بوده كه بـا هــدف

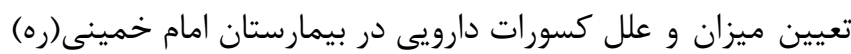

\section{مقدمه}

سلامت بهتر، اساس فلسفهى وجود سيستمهاى بهداشـت و درمـان بوده و بدون شك اين موضوع به عنوان هدف اصلى و معنسى دار ايـن

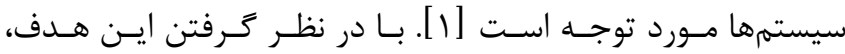
سازمانهاى حامى سلامت به دليل رقابت بر سر ارائسهى خـدمات از طريق روشهاى مقرون به صرفه از نظر اقتصادى، سياسى و قـانونى

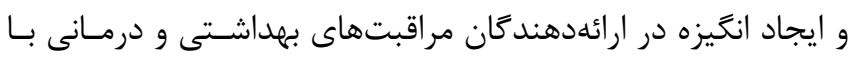

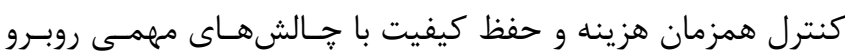

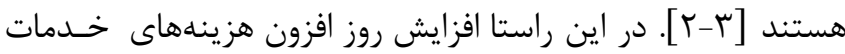

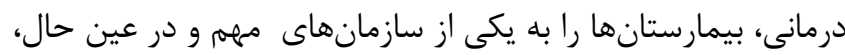

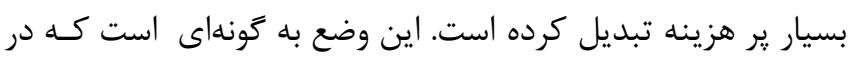

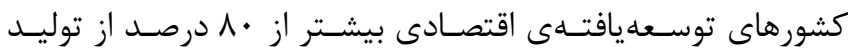

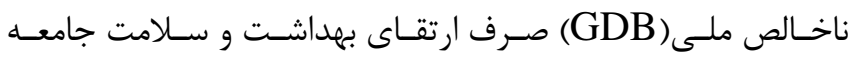

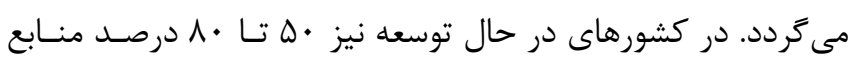

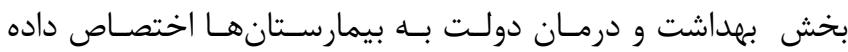

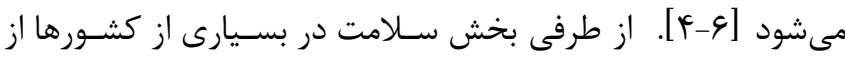

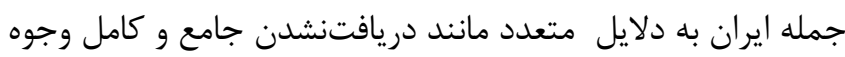

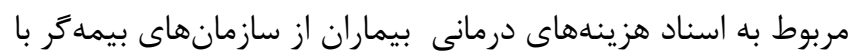

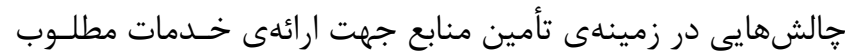

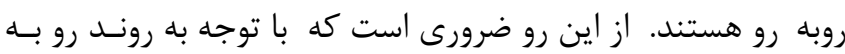

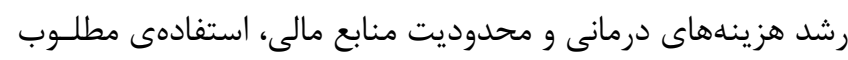

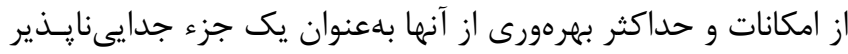

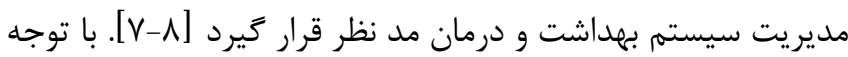

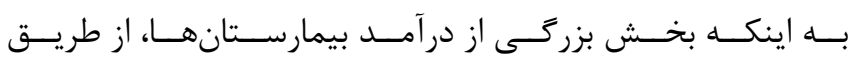

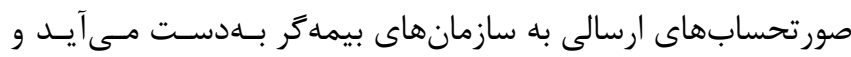

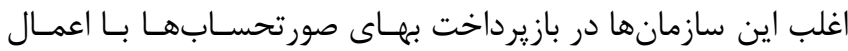

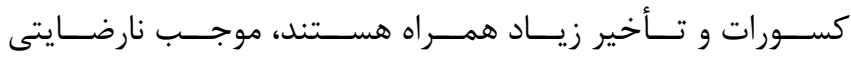

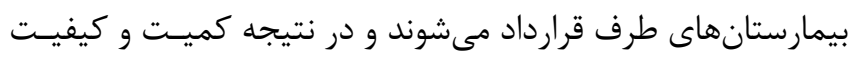

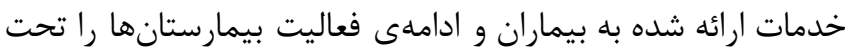

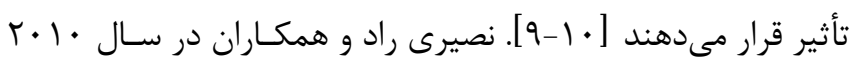

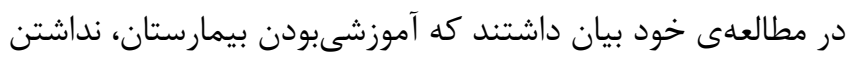
تجربهى كافى يرسنل مراقبتى براى تكميل يروندهى بيمـاران، ورود

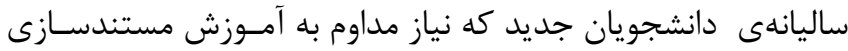

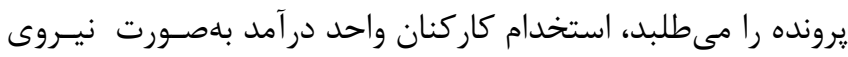

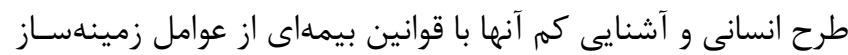

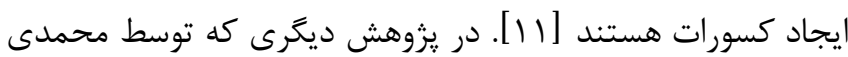


با بيمهى درمانى از نوع تأمين اجتماعى، سـلامت و كميتــى امـداد

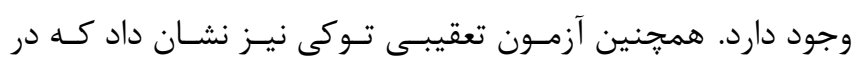

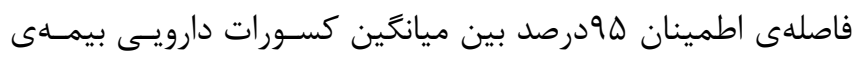

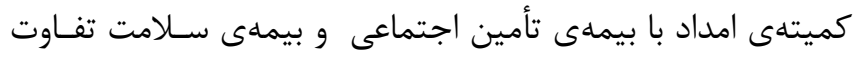

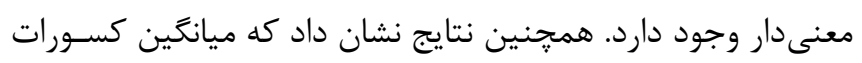

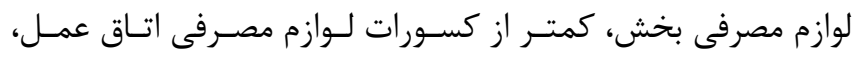

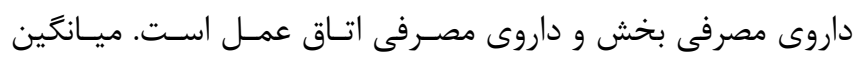

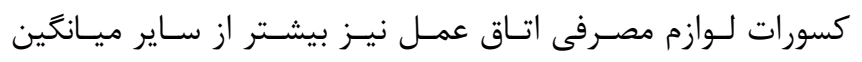

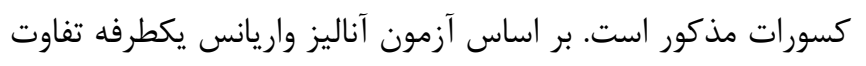

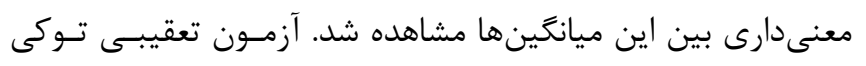

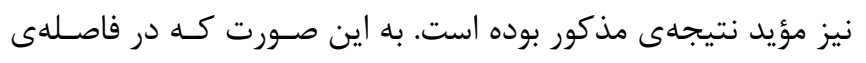

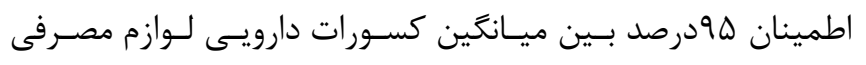

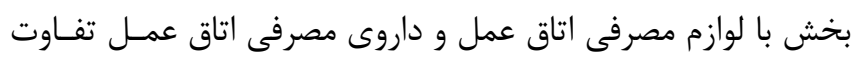

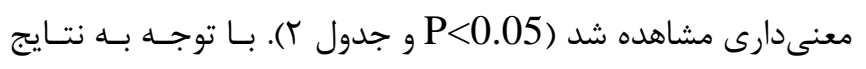

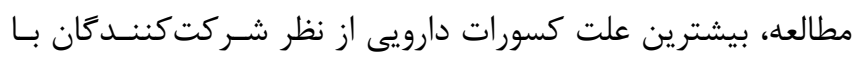

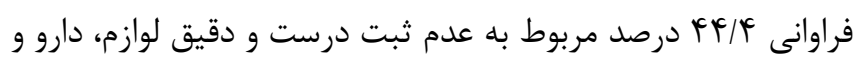

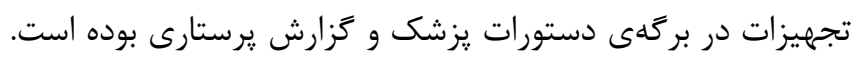

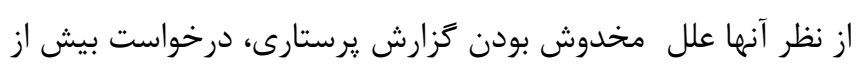

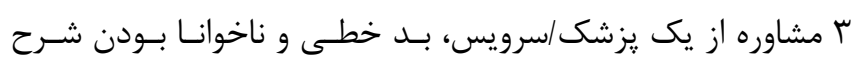

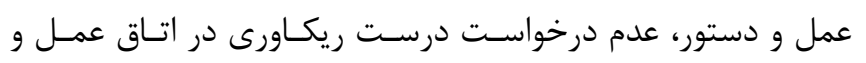

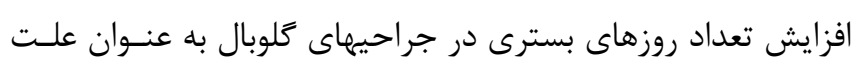

$$
\text { كسورات دارويى محسوب نمى شوداد }
$$

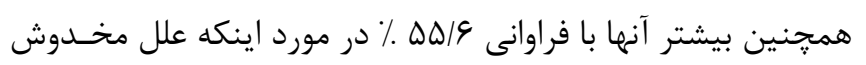

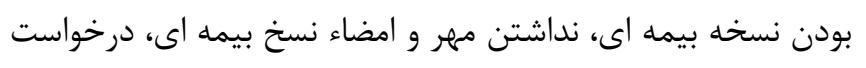

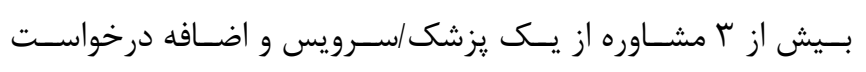

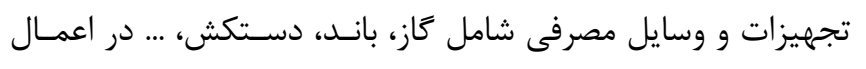

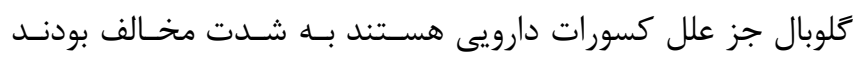

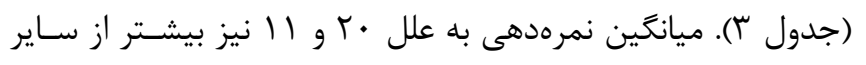

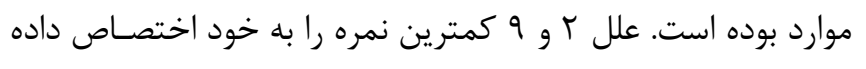

است (شكل ()).

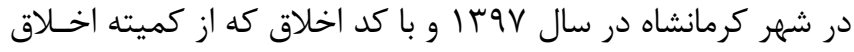

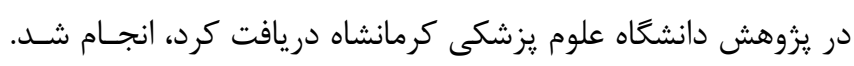

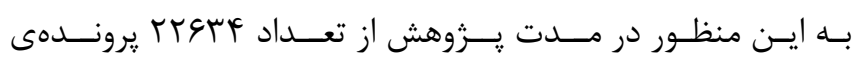

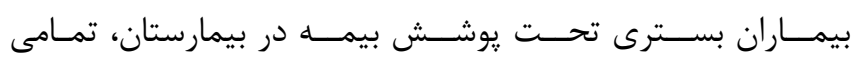

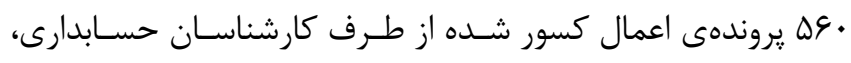

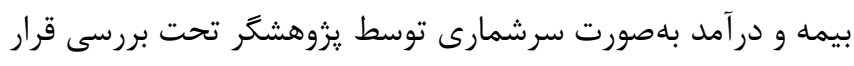

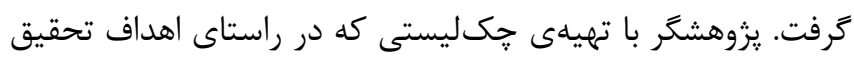

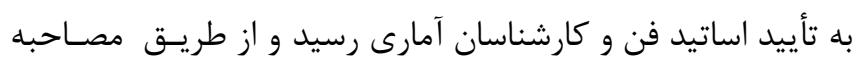

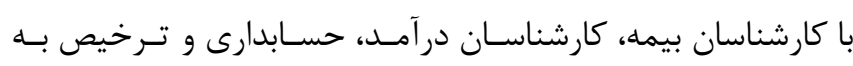

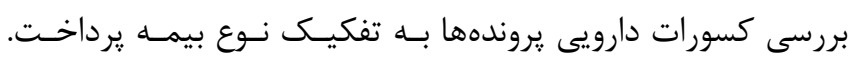

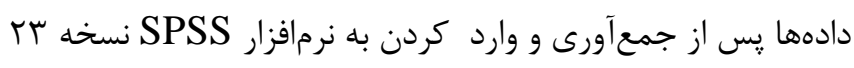

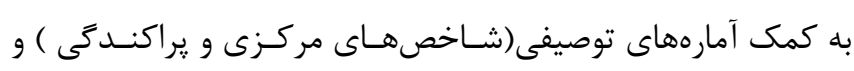

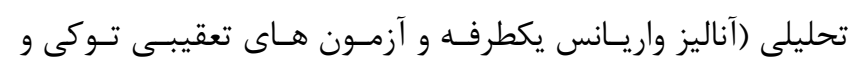

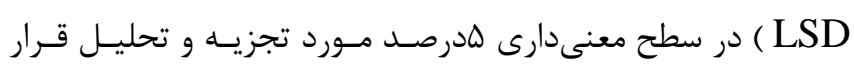

كرفتند.

\section{يافتهها}

نتايج يروهش حاضر نشان داد كه ميانكَين و انحراف معيار كسـورات

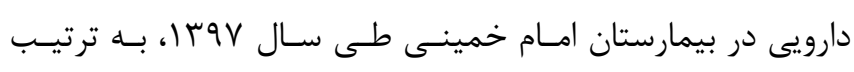
19099VAT/9.9.

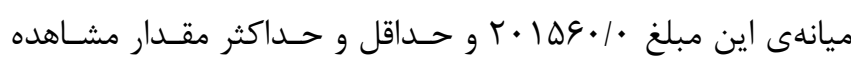

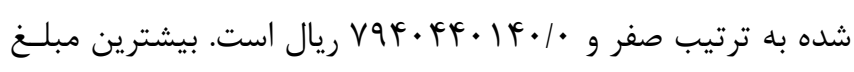

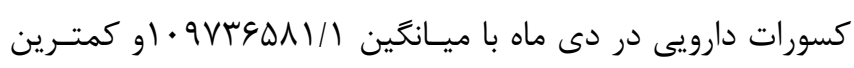

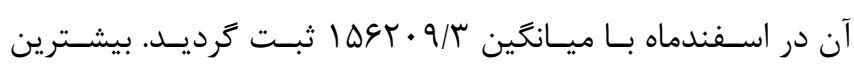

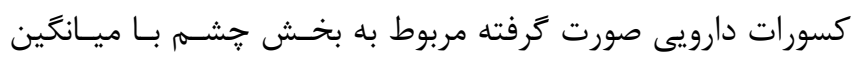
.

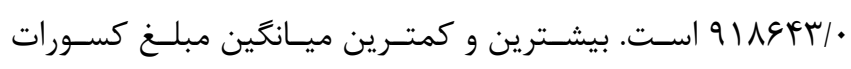

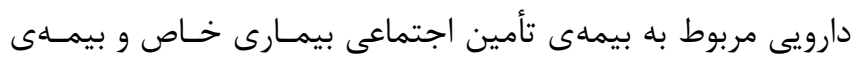

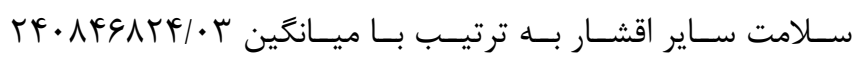

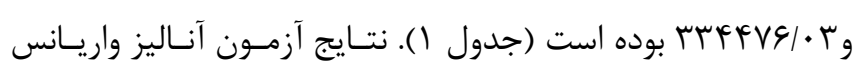

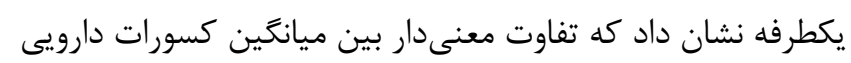




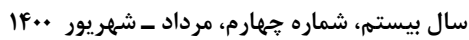

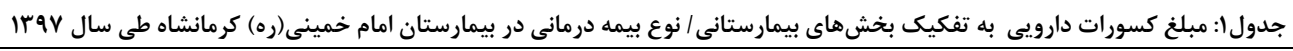

\begin{tabular}{|c|c|c|c|c|}
\hline حداكثر & حداقل & ميانه & ميانگين & \\
\hline $11 \cdot 1 r v \cdot r r$ & rQI. & rVF... & 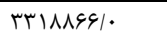 & ICU \\
\hline $\mid \Delta T \cdot \varphi \& \Lambda$. & . & $r \cdot 99 . r$ & $11 r 9 \Delta 9 \% / 9$ & داخلى \\
\hline fIIrqDING & $19 \cdot 4$ & $1 \cdot r t \cdot 1$ & 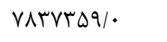 & اورخانس (بسترى) \\
\hline GITTDQIT & ४^q & $999 .$. & rIVYGG9/V & اورزانس (تحت نظر) \\
\hline IrITVQVT & $r \cdot r \Delta$ & TYNIQN & $\| \Delta V \cdot r \varepsilon \mid \cdot$ & جراحى \\
\hline Vqq.FF.lf. & rVTr & raAMA. & Q. TYTLTF/. & جشم \\
\hline$\Delta \Lambda \& q \cdot r r$. & 19. & 111.19 & TITAFIQ/I & سوختى \\
\hline$r \Lambda \cdot q \cdot \Delta V \Delta$ & $1 v 99$ & $\mid r \Lambda \ldots$ & 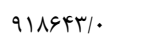 & 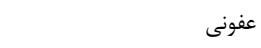 \\
\hline حداكثر & حداقل & 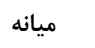 & ميانغين & نوع بيمه \\
\hline VqF. Fq. If. & $r \wedge \cdot \Lambda$ & $\wedge \varepsilon \ldots$ & $r F \cdot \Delta F G \Lambda T F / \cdot r$ & تأمين اجتماعى بيمارى خاص \\
\hline GITTDQIT & 19. & ivrus. & $I V V \cdot r \cdot q / V$ & تأمين اجتماعى \\
\hline$\Delta F \Delta \cdot q V .$. & $r \cdot r \Delta$ & rrqDF. & |DTGQVQ/r & سلامت روستايى \\
\hline ratrutaq & $r \cdot r \Delta$ & ITNTF. & $r \Lambda 1190 / 9$ & سلامت روستايى بدون ارجاع \\
\hline$r q \ldots .$. & rVT & $१ ९ \cdot \vee \vee$ & TrEFVG/.r & سلامت ساير اقشار \\
\hline 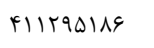 & . & rی.r. & V.rIIG9/9 & سلامت همعانى \\
\hline ritvar.. & . & rVAF.. & IFIAVAN/T & سلامت كارمندى \\
\hline$r \Delta \cdot r \Delta F$. & $4 \wedge 9$ & ५१९९. & rGसTQN/9 & كميته امداد \\
\hline rrIV.qF & rqqA & rrI.ru & $91 Y I 10 / \Delta$ & تأمين فوتى \\
\hline II.IrV.rt & 19.4. & $\Delta F M A$ & FAFITDQ/F & تأمين ونتيلاتور ICU \\
\hline $1999 \ldots$ & $r .419$ & $1198 .$. & $4 \Lambda \cdot 9 q \mu / D$ & سلامت ايرانيان \\
\hline
\end{tabular}

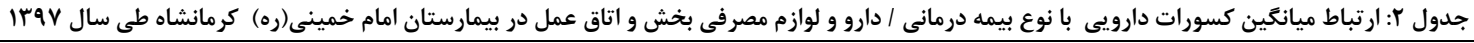

\begin{tabular}{|c|c|c|c|c|c|}
\hline P-Value & اختلاف ميانكينها و فاصله اطمينان هودرصد ( لوا) & نوع بيمه(J) & $\begin{array}{l}\text { P-Value } \\
\end{array}$ & ميانكَين & \\
\hline - /AFr & $(-\cdot / \Delta T \cdot r g \cdot / r T V),-\cdot / 1 \cdot 19 \Lambda$ & 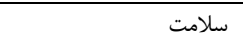 & $* \cdot . \cdot r r$ & rIDLGATV/G & تأمين اجتماعى \\
\hline$* * . / . r 4$ & $(\cdot / .9 \Delta, r / V \cdot .4), 1 / \wedge 9 \vee \wedge$. & كميتهى امداد & & 1 & \\
\hline - /AFt & $(-\cdot / r T V, \cdot / \Delta r \cdot r), \cdot / 1 \cdot 19 \Lambda$ & تأمين اجتماعى & & $r . . g \times q) / A$ & 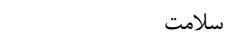 \\
\hline$* * . / . r \Delta$ & $(\cdot / / 9 \wedge r, r / \Lambda \cdot \cdot \Lambda), 1 / 9994 \wedge$ & كميتهى امداد & & $107 / 41 / 1 / 1$ & \\
\hline$* * . / .48$ & $(-r / V \cdot \cdot q,-\cdot 1 \cdot 9 \Delta), g-1 / \Lambda 9 \gamma \wedge$. & تأمين اجتماعى & & & كميته امداد \\
\hline$* * . / . r \Delta$ & $(-\cdot / / 9 \wedge r,-r / \Lambda \cdot \cdot \Lambda),-1 / 999 \uparrow \wedge$ & 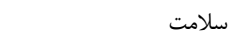 & & TEसT91/9 & \\
\hline P-Value & اختلاف ميانغين ها و فاصله اطمينان هودرصد ( لوا) & دارو و لوازم مصرفى(J) & P-Value & 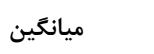 & دارو و لوازم مصرفى(I) \\
\hline$\cdot / 119$ & $(-\cdot / \cdot \Lambda \Delta, \cdot / V V \Delta T), \cdot / r F \Delta \cdot V$ & 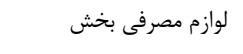 & $* \cdot / \cdot r q$ & & 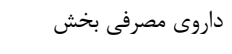 \\
\hline$\cdot / 4 \vee 9$ & (- & 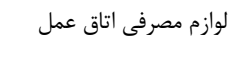 & & $\Delta T Y I G \mid F / T$ & \\
\hline$\cdot / 1 \Delta \mid$ & $(-1 / r q 91, \cdot / r \cdot 11),-\cdot / \Delta q q .$. & 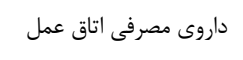 & & & \\
\hline .1119 & $(-\cdot V V \Delta T, \cdot / \cdot \Lambda \Delta),-\cdot / r F \Delta \cdot V$ & 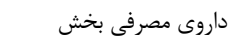 & & & 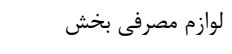 \\
\hline **./.tr & $\left(-\cdot / 994 r_{g}-\cdot / .4 \cdot \Lambda\right),-\cdot / \Delta T V \Delta V$ & ل لوازم مصرفى اتاق عمل & & $\| 19 \Lambda Y \cdot 91 \Lambda$ & \\
\hline$* * . / .19$ & $(-1 / 91 \wedge \Delta,-\cdot / 1999),-\cdot / \Lambda 94 \cdot V$ & داروى مصرفى اتاق عمل & & & \\
\hline$\cdot /|\Delta|$ & $(-\cdot / r \cdot 1), g / / r q q 1), \cdot / \Delta q q \cdot$. & داروى مصرفى بخش & & & داروى مصرفى اتاق عمل \\
\hline$* * . / \cdot 19$ & $(\cdot / 1999,1 / 91 \wedge \Delta), \cdot / \wedge 94 \cdot \vee$ & 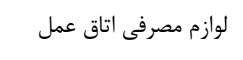 & & 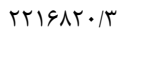 & \\
\hline$\cdot / \pi \Delta 1$ & $(-\cdot / F \cdot \Delta r, \cdot / \mid r \Lambda I), \cdot / r 99 \Delta$. & داروى مصرفى اتاق عمل & & & \\
\hline$\cdot / 4 \vee q$ & $(-\cdot / r T r|, \cdot| q \Lambda \Lambda \mid), \cdot / 1 \Lambda T \Delta$. & 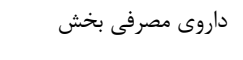 & & & 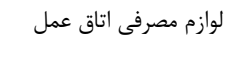 \\
\hline **./.tr & $(\cdot / \cdot 9 \cdot 1, \cdot / 99 F T), \cdot / \Delta T V \Delta V$ & 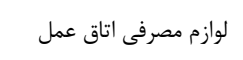 & & $q 9 \psi \cdot \varphi \lambda \cdot \varphi / \cdot \Delta$ & \\
\hline$\cdot|K \Delta|$ & $(\cdot / 4 \cdot \Delta r,-1 / / r \Lambda I),-\cdot / r 99 \Delta \cdot$ & داروى مصرفى اتاق عمل & & & \\
\hline
\end{tabular}


نشريه يخوهشكده علوم بهداشتى جهاددانشعاهى

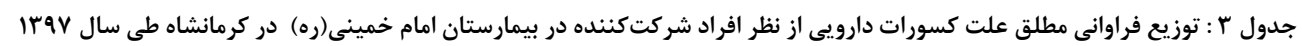

\begin{tabular}{|c|c|c|c|c|c|c|c|}
\hline \multirow[b]{2}{*}{ خيلى موافق } & \multicolumn{3}{|c|}{ ياسخ } & & \multirow[t]{2}{*}{ ميانََين(انحر اف معيار) } & \multicolumn{2}{|l|}{ علل كسورات دارويى از نظر شركتكنندَان } \\
\hline & 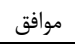 & نظرى ندارم & 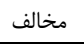 & خيلى مخالف & & & \\
\hline$\overline{r r / r}$ & $\cdot$ & $\cdot$ & Tr/T & $F+/ 4$ & $(1 / \wedge \vee \Lambda) Y / \Delta S$ & مخدوش بودن تاريخ / يا تاريخ اعتبار بركههاى بيمه اى & 1 \\
\hline $11 / 1$ & · & · & r & $\Delta \Delta / 9$ & $(1 / r \cdot r)) / V \Lambda$ & مخدوش بودن نسخه بيمه اى / در صورت مخدوش بودن & r \\
\hline & & & & & & ي مشت نويسى شود & \\
\hline$r \pi / r$ & · & $11 / 1$ & . & $\Delta \Delta / 9$ & $(1 / 9 Y Y) Y / \Delta G$ & نداشتن مهر و امضاء نسخ بيمه اى & r \\
\hline 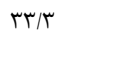 & · & $r T / r$ & $11 / 1$ & r & $(1 / V G Y) Y / \wedge q$ & دستواشت ميزر و امضاء / مغايرت امضاء و يا فقط زدن مهر در & r \\
\hline$t r / T$ & $11 / 1$ & r/r & tr/T & $11 / 1$ & $(1 / T G \varphi) r / I 1$ & مخدوش بودن دستورات يزشك & $\Delta$ \\
\hline . & $11 / 1$ & $r T / r$ & $99 / \mathrm{V}$ & . & $(\cdot / N Y G) T / F Y$ & مخدوش بودن كَزارش يرستارى & 4 \\
\hline$r T / 4$ & $11 / 1$ & r & . & r & $(1 / 919) r / \wedge 9$ & ديزشك رنك بودن نسخه بيمه اى / دو رنغ بودن دستورات & $\checkmark$ \\
\hline$r r / r$ & $11 / 1$ & $r r / r$ & · & $r t / T$ & rr/ & عدم درخواست مشاوره در دستورات يزشك & $\wedge$ \\
\hline . & $11 / 1$ & $11 / 1$ & tr/T & $\Delta \Delta / \varphi$ & $(1 / \cdot 9 \Gamma)) / V \wedge$ & درخواست بيش از r مشاوره از يك يزشك / سرويس & 9 \\
\hline$r T / T$ & $11 / 1$ & $11 / 1$ & $r r / r$ & $r T / r$ & $(1 / \Delta G Y) T / V \Lambda$ & عدم يرداخت بيش از يك ويزيت در روز & 1. \\
\hline$r r / r$ & $r \mu / r$ & · & $r r / r$ & . & $(1 / \pi T H) H / Q V$ & عدم تكميل درست شرح عمل ها توسط يزشك معالج & 11 \\
\hline$r \mu$ & $r T / T$ & $11 / 1$ & r & . & ع & 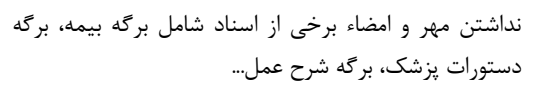 & ir \\
\hline tr/T & $\cdot$ & r/r & 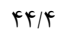 & . & $(1 / T r Q) r$ & عدم ثبت كد هاى بيمه اى يروسيجرهاى انجام شده & ir \\
\hline tr/T & $r T / r$ & $r e / s$ & $11 / 1$ & . & $(1 / \cdot \mid q) \tilde{f} / \Delta \varphi$ & عدم تطابق كدهاى ثبت شده با شرح عمل ها & If \\
\hline$\cdot$ & $11 / 1$ & $r r / r$ & $\Delta \Delta / 9$ & · & $(\cdot / V Y \varphi) Y / \Delta \varphi$ & بد خطى و ناخوانا بودن شرح عمل و دستور & 10 \\
\hline $11 / 1$ & $r T / r$ & $11 / 1$ & $r T / r$ & $r$ & $(1 / \Delta \cdot 9) r / \Delta 9$ & عدم ثبت ساعت ورود و خروج بيمار به اتاق عمل & 18 \\
\hline$r T / T$ & $11 / 1$ & . & $F+/ f$ & rT/T & $(1 / \Delta \Lambda 1) r / 9 V$ & منشى اتاق عمل مدت زمان عمل ثبت شده بين جراح، بيهوشى و & iv \\
\hline$r T / 4$ & $\cdot$ & $11 / 1$ & r & r & $(1 / \Delta q) r / F F$ & بيهوش. بت صحيص ساعت شروع و پايان عمل در بركه هارت & 11 \\
\hline . & · & $r T / r$ & $\Delta \Delta / 9$ & $r T / T$ & $(\cdot / v \cdot v) r$ & عدم درخواست درست ريكاورى در اتاق عمل & 19 \\
\hline$\mu+/ /^{\circ}$ & $r T / r$ & . & Tr/T & . & $(1 / r q q) r / V \Lambda$ & 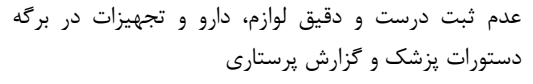 & $r$. \\
\hline $11 / 1$ & $r \mu / r$ & $r e / s$ & . & $11 / 1$ & r & 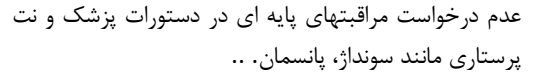 & rI \\
\hline Tr/T & $11 / 1$ & r/r & · & r/r & $(1 / 919) r / 19$ & انجام ميشوند كليه بروسيجرهايى كه در بخش ها / يا اوررانس & rt \\
\hline$T r / 4$ & $11 / 1$ & $11 / 1$ & $11 / 1$ & 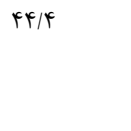 & $(I / V Y) T / \Delta \varphi$ & 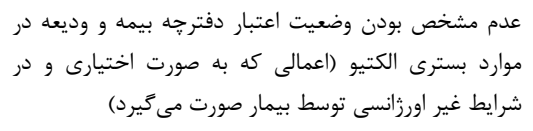 & r \\
\hline$\cdot$ & $11 / 1$ & $r T / r$ & r & r & $(1 / \cdot \Delta F) r / 11$ & 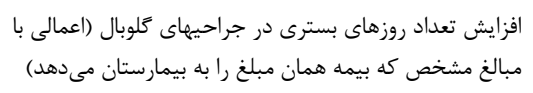 & re \\
\hline $11 / 1$ & . & $r \mu$ & . & $\Delta \Delta / 9$ & $(1 / F \Delta T) Y / I I$ & دستكش، ... در اعمال تلكيال و وسايل مصرفى شامل كاز، باند، & $r \Delta$ \\
\hline
\end{tabular}




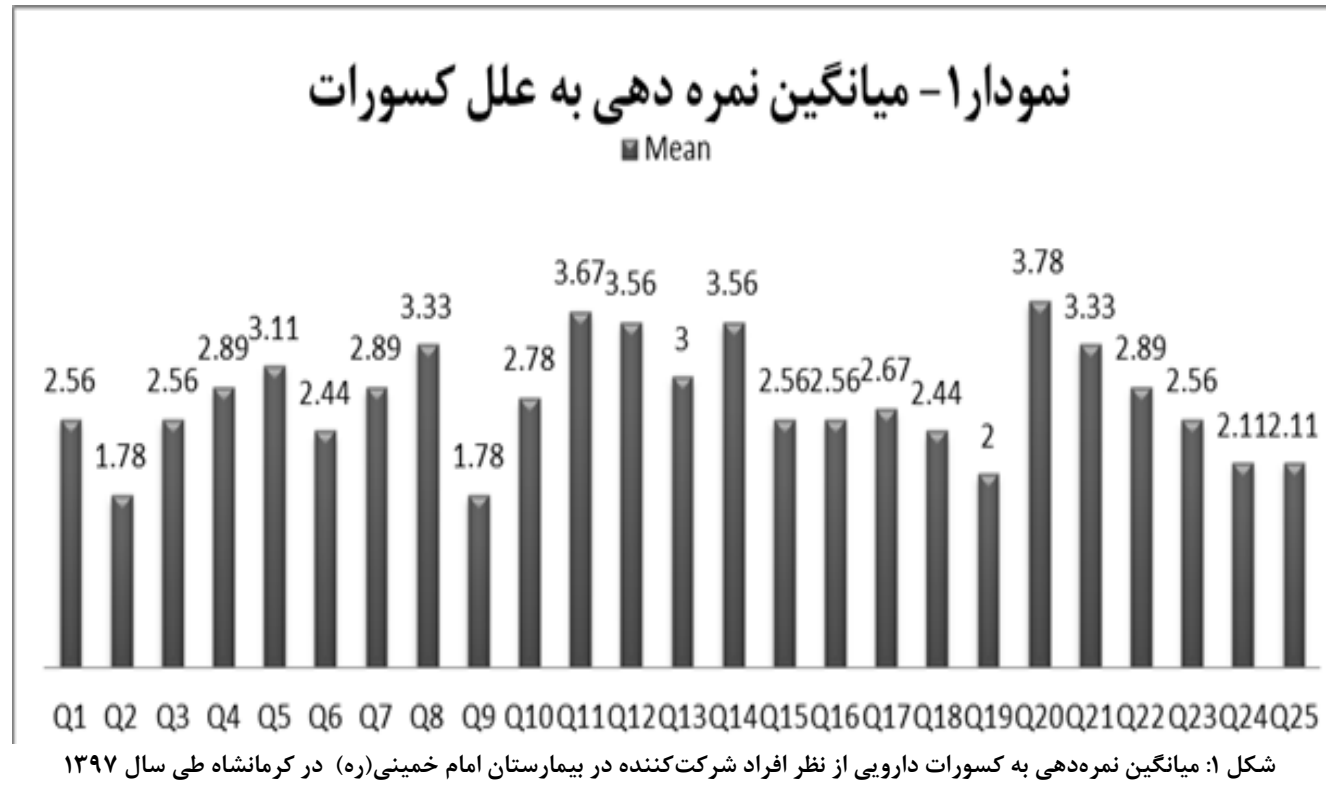

كمترين مقدار كسورات مربوط به نسخ سـريايى داروخانـهـ كَزارش

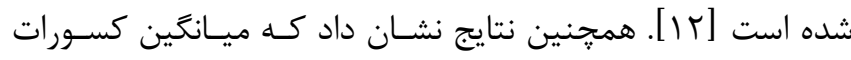

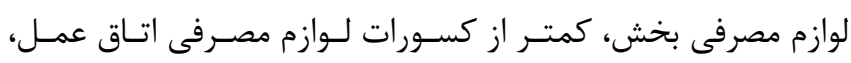

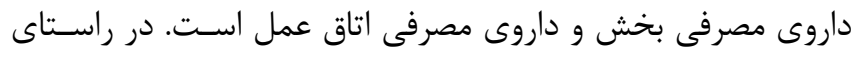

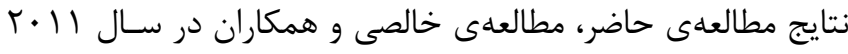

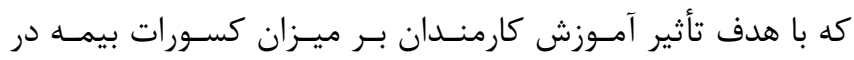

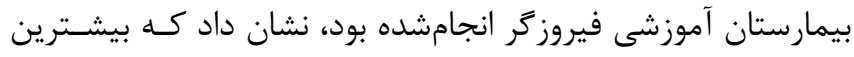

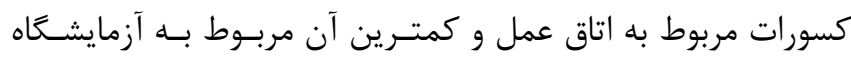

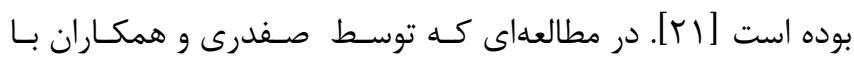

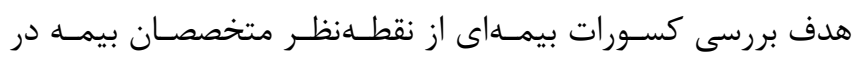
بيمارستانهاى آموزشى دانشخاه علوم يزشكى مشهد انجام شده بودي،

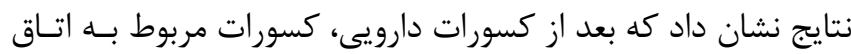

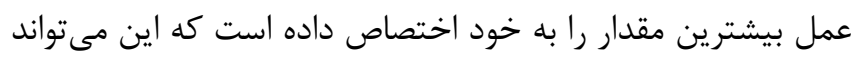

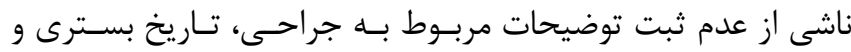

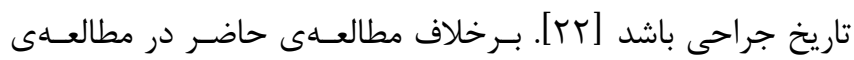

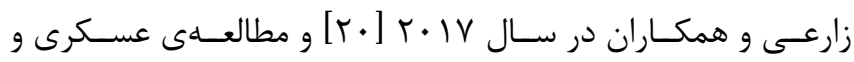

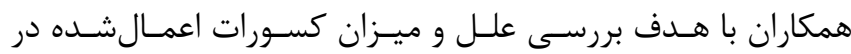

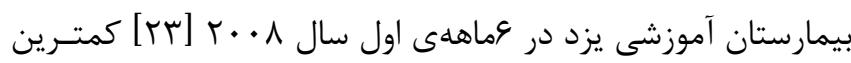

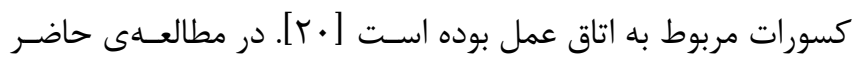

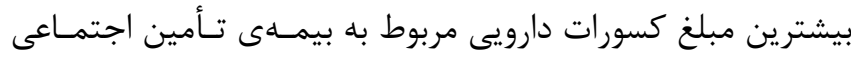

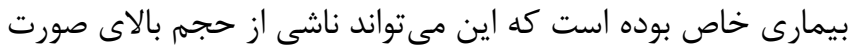

بحث و نتيجه گيرى

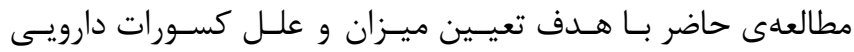

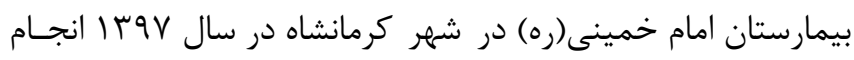

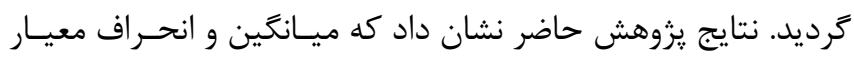

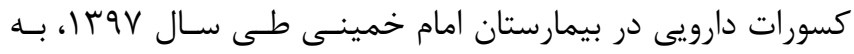

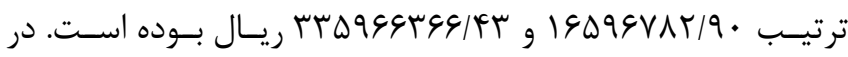

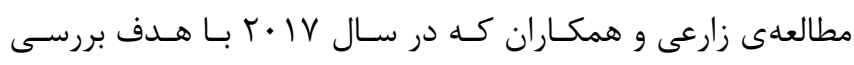

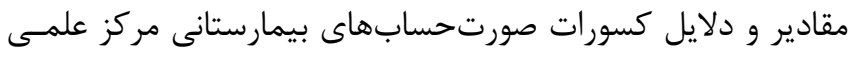

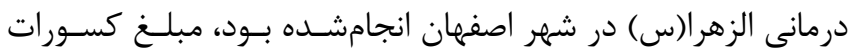

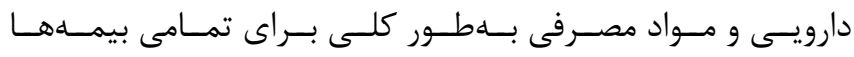

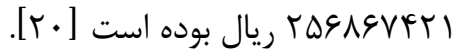
در اين مطالعه بيشترين مبلغ كسورات دارويى در دى ماه و كمترين

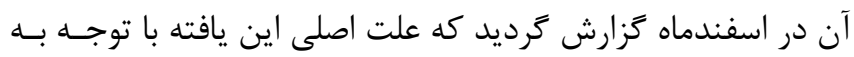

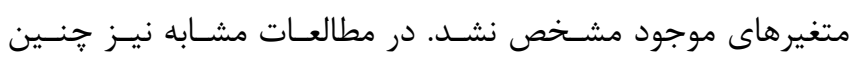

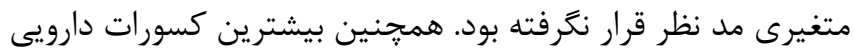

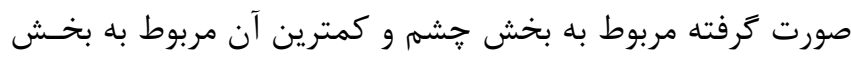

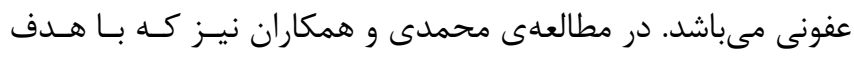

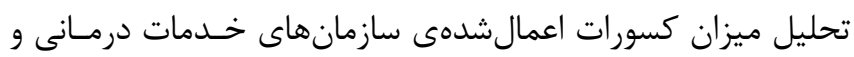

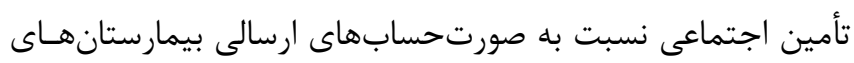

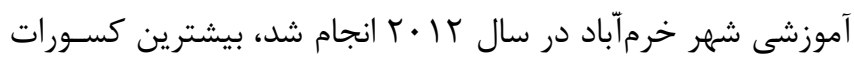

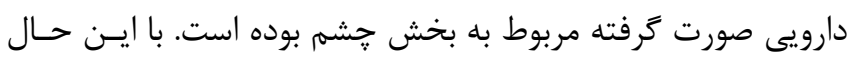


داروها و تجهيزات در داروخانه از دلايـل اصـلى كسـورات دارويسى و

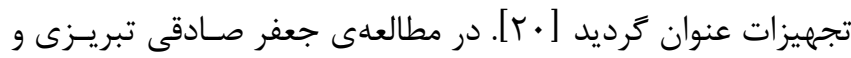

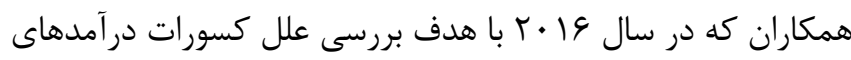

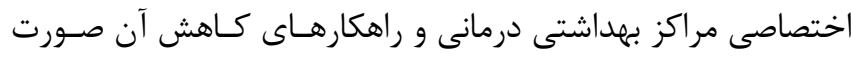

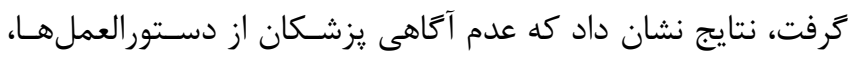

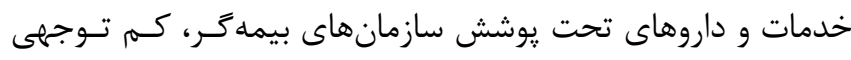

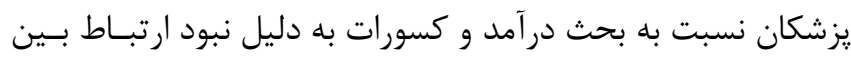

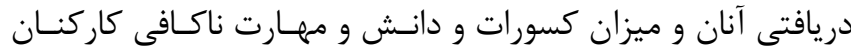

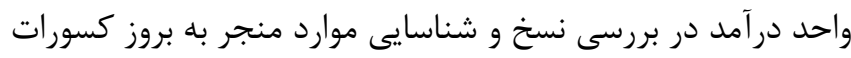

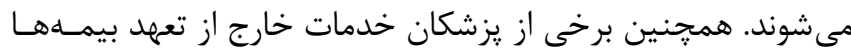

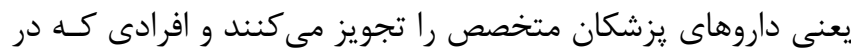

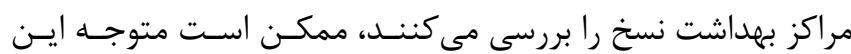

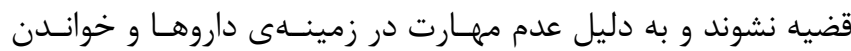

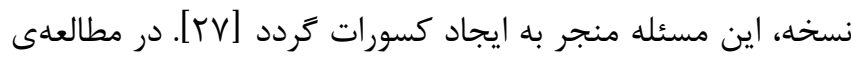
Bhatia و Krushat

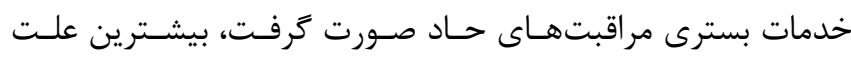
كسورات يرداختهاى بيمهى Medicare مربوط به ارائهى خدمات

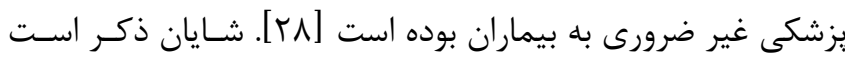

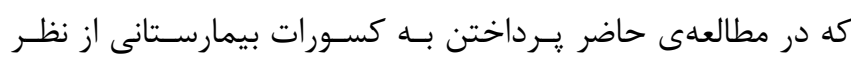

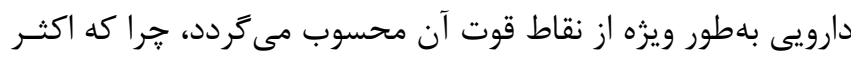

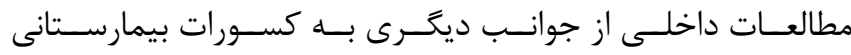

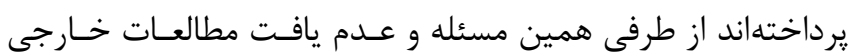

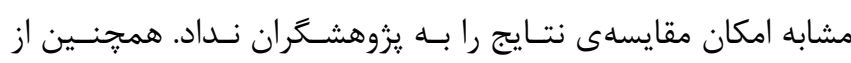

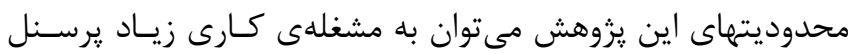

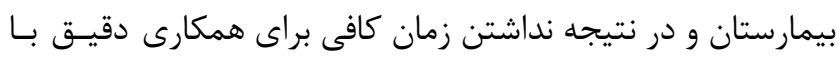

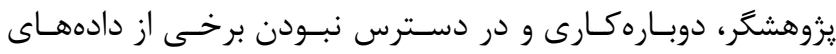

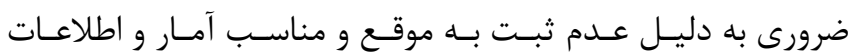

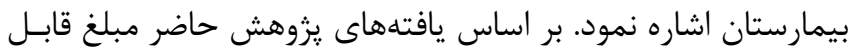

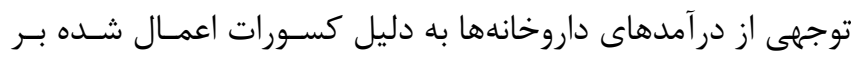

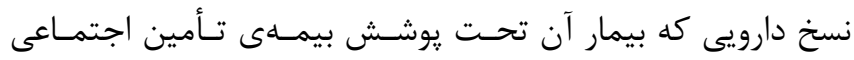

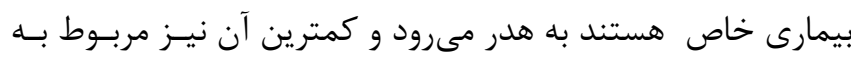

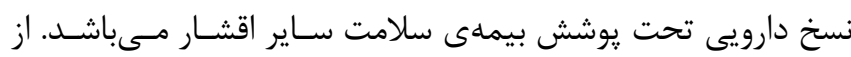

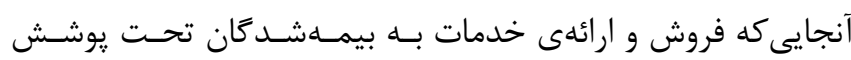

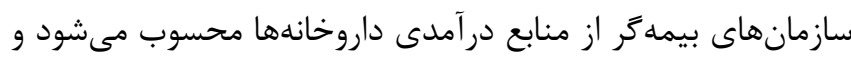

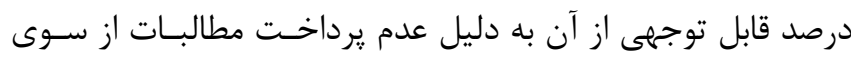

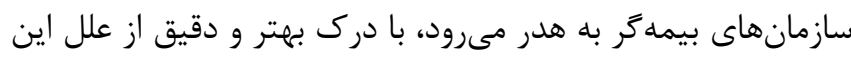

حسابهاى اين بيمه باشد. در مطالعهى سروستانى و همكاران كه با هدف بررسى مقــدار و علـل كسـورات بيمـهاى بيمارسـتان شـهـداى

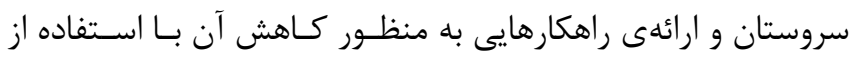

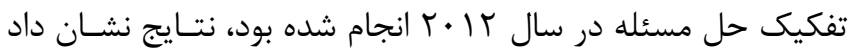
كه بيشترين درصد كسورات بيمارستان شهداى سروستان مربوط به آنهان

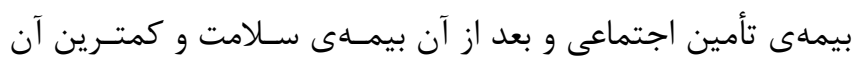

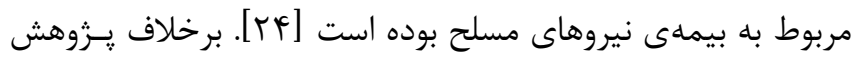

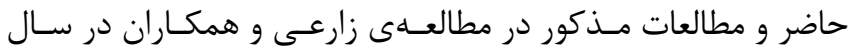

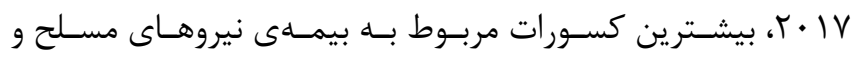

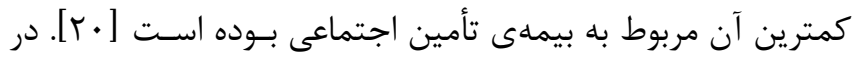

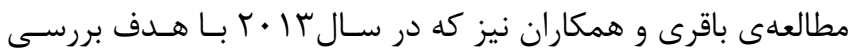

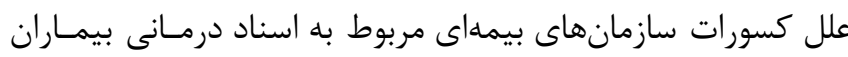

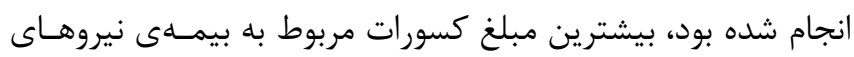

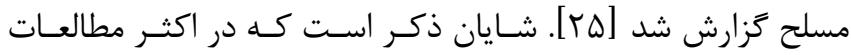

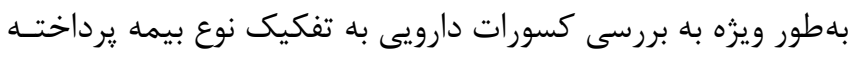

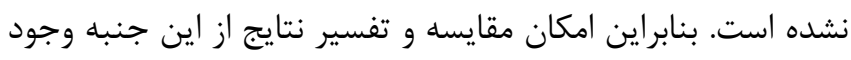

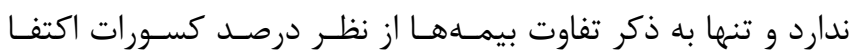

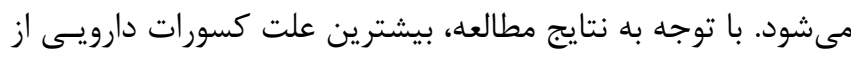

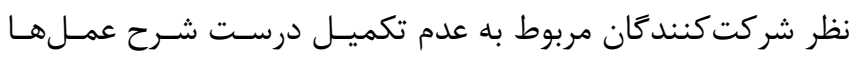

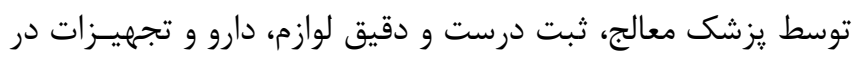

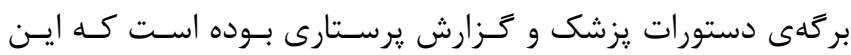

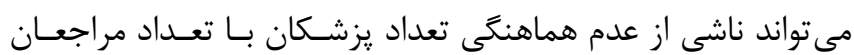

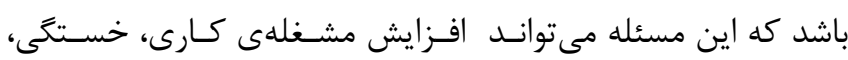

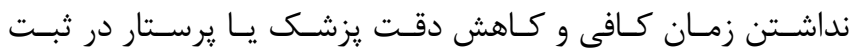

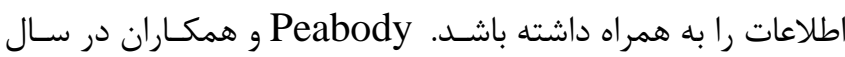

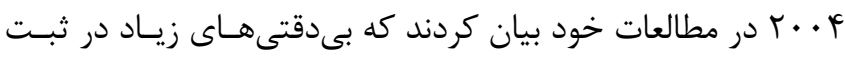

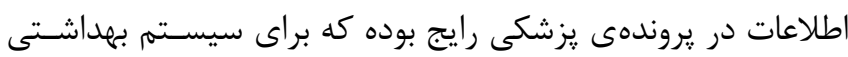

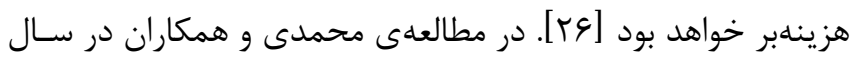

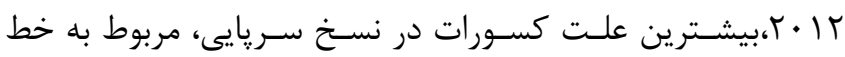

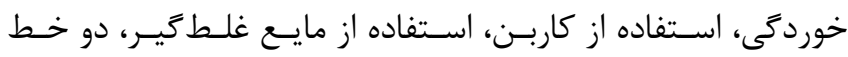

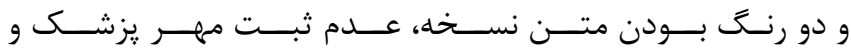

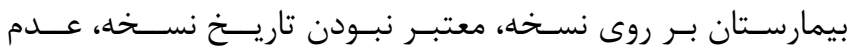

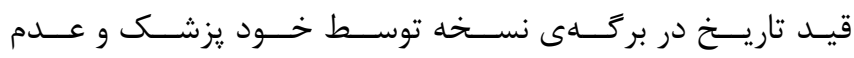

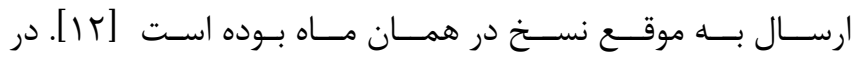
مطالعهى زارعى در سال VI ا. T، علت اصلى كسورات دارويس، عـدم

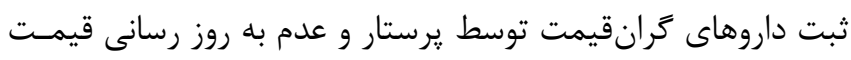


نواقص يرونده مى تـوان مشـكلات ناشسى از كنتـرل هزينـهى دارو را

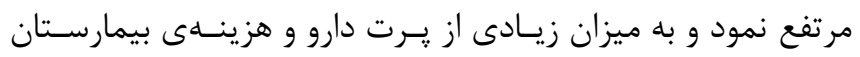

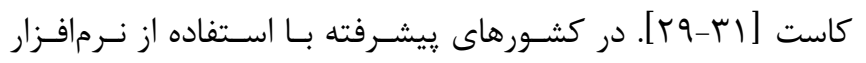

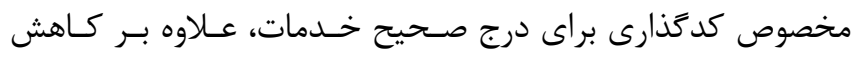

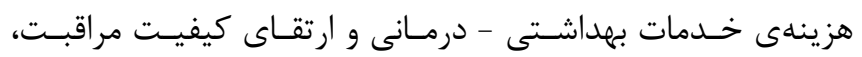

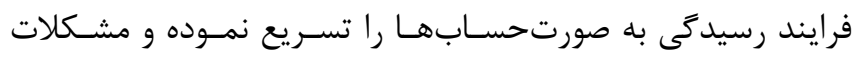

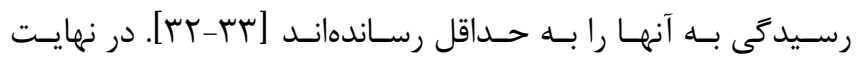

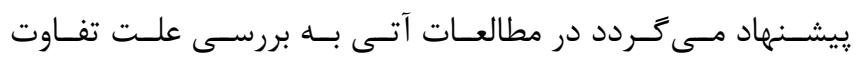

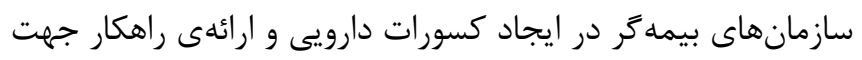

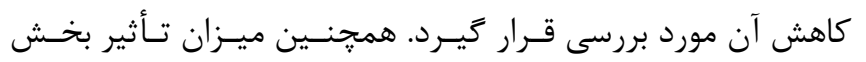

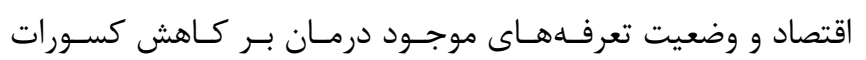
دارويى مورد توجه قرار كيرد..

\section{سمم نويسند}

نام بهنام رضا مخصوصى: طراحى و اجراى مطالعه حسين اميرى: همكارى در طراحى مطالعه

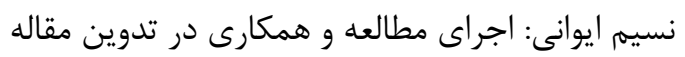
شرمين رحمانى: تحليل نتايج، تدوين و ويرايش مقال مطاله

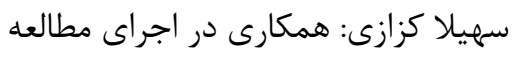

\section{تشكر و قدردانى}

اين مقاله ماحصل انجام طرح تحقيقـاتى مصـوب معاونـت يزوهشئى

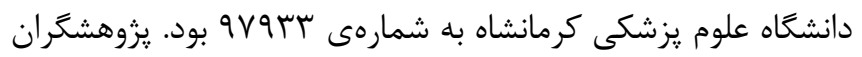

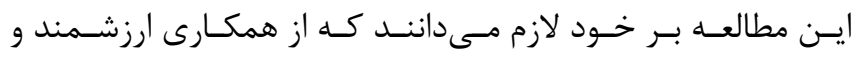

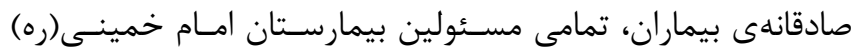

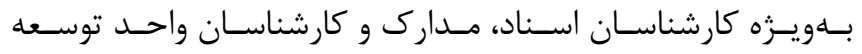

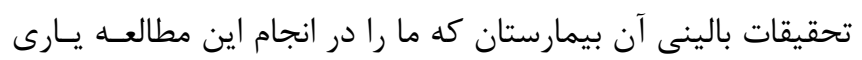
نمودند، كمال تشكر و قدردانى را داشته باشد.

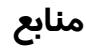

1. Kieny MP, Bekedam H, Dovlo D, Fitzgerald J, Habicht J, Harrison G, Kluge H, Lin V, Menabde N, Mirza Z, Siddiqi S. Strengthening health systems for universal health coverage and sustainable development. Bulletin of the World Health Organization 2017;95:537-539

2. Simon R, Morarji A, Ganesamurthy K. Disaster Management-Hospital perspective.
دسته از كسورات مسىتـوان كـارايى داروخانـهـ و در نهايـت كيفيـت

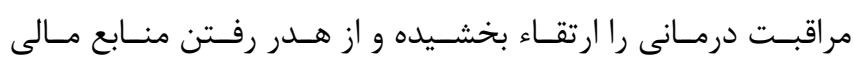

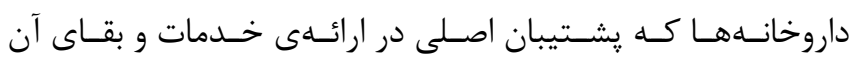

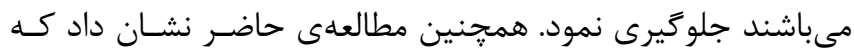

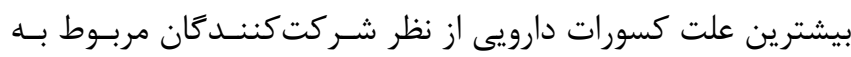

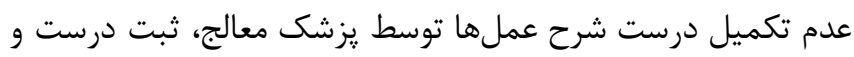

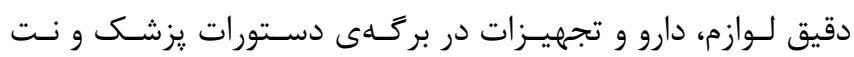

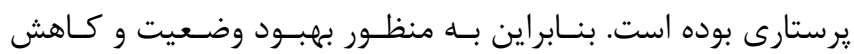

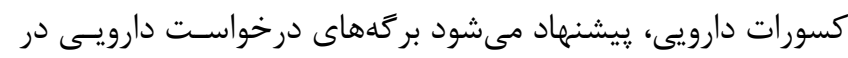

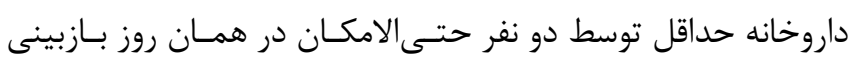

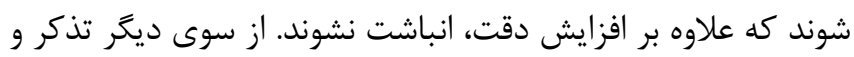

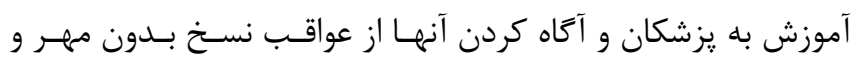

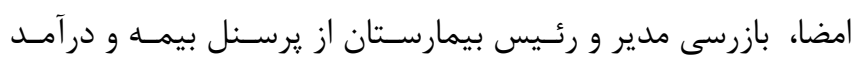

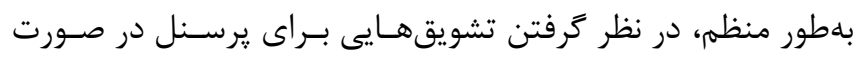

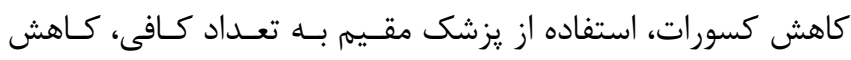

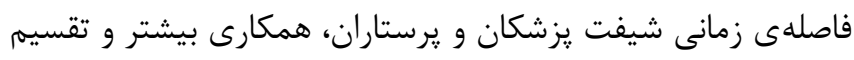

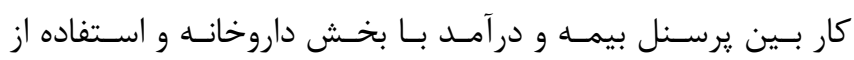

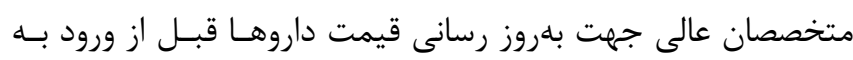

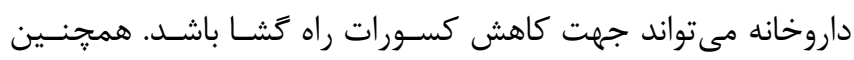

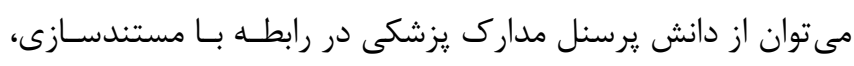

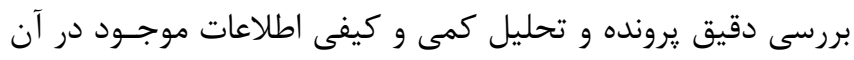

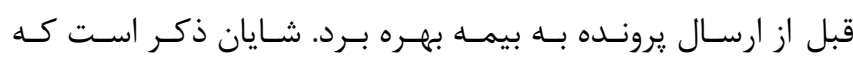

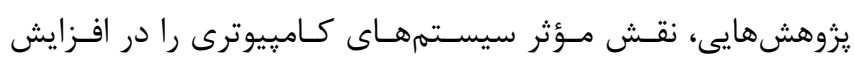

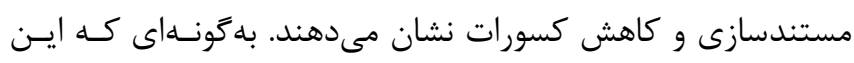

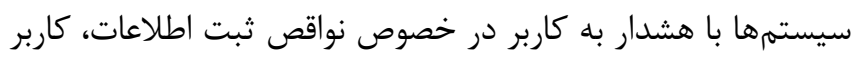

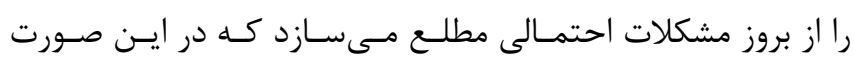

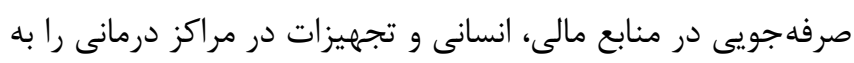

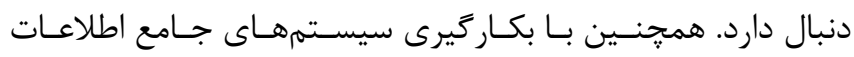

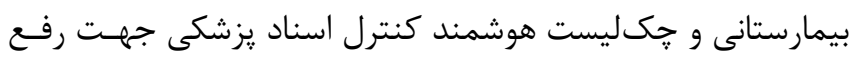

International Journal of Research and Analytical Reviews 2021;8:390-394

3. Khorrmmi F, Hosseini Eshpala R, Baniasadi $\mathrm{T}$, Azarmehr N, Mohammadyi F. Prioritizing insurance deductions factors of Shahid Mohammadi hospital inpatients records using Shannon Entropy. Hormozgan Medical Journal 2013; 17: 77-82 [Persian] 
4. Goense L, Van Dijk WA, Govaert JA, van Rossum PS, Ruurda JP, van Hillegersberg R. Hospital costs of complications after esophagectomy for cancer. European Journal of Surgical Oncology (EJSO) 2017;43:696-702

5. Edemekong $\mathrm{P}$, Annamaraju $\mathrm{P}$, Haydel $\mathrm{M}$. Health Insurance Portability and Accountability Act. Treasure Island (FL). 1st Edition, StatPearls Publishing: Island, 2021

6. Mohtasham Amiri Z, Rahimi Kalamroudi H, Davoudi A. Unit Analysis of Health Care Centers in Urban and Rural Area of Guilan. Journal of Guilan University of Medical Sciences 2008; 17: 24-32 [Persian]

7. Wolff J, Heister T, Normann C, Kaier K. Hospital costs associated with psychiatric comorbidities: A retrospective study. BMC health services research 2018;18:1-7

8. Fechtel RB, Fullenkamp C. Life Insurance Policy Disclosure for the 21st Century. Journal of Financial Service Professionals 2021;75:36-58

9. Mohamaadi E, Oliaeemanesh A, Zanganeh M, Nadarkhani F, Ghanati E, Yousefinezhadi T, Tabatabaei SM. Investigating the Rate and Causes of Hospital Deductions and Determining its Reduction Strategies in Iranian Hospitals. The Iranian Journal of Health Insurance 2020;3:92-103 [Persian]

10. Mosadegh rad AM, Esfahani P, \& Nikafshar M. Hospitals' Efficiency in Iran: A systematic review and meta-analysis of two decades of research. Payavard 2017; 11: 318-331 [Persian]

11. Nasiri rad $\mathrm{N}$, Rashidian A, Joudaki $\mathrm{H}$, Haghighi FA, Arab M. Assessing issues and problems in relatioship between basic insurance organizations and university hospitals: A qualitative research. Hospital 2010; 9: 8-18 [Persian]

12. Mohammadi A, Azizi AA, Cheraghbaigi R, Mohammadi R, Zarei J \& Valinejadi A. Analyzing the deductions applied by the medical services and social security organization insurance toward receivable bills by university hospitals of Khorramabad. HealthInformation Management 2012; 10: 172-180

13. Afshari M, Mosadeghrad A, Arab M. The impact of quality management on reducing bill deductions at operating theatre department of Valiasr hospital a participatory action research. Journal of Hospital 2017;16:93-101 [Persian]

14. Mosadeghrad A, Afshari M, Nasrolahi R, Daneshgar S, Corani Bahador R. The Impact of Health Transformation Plan on Deductions Imposed on Imam
Khomeini Hospital Complex's Bills. Journal of Hospital 2018; 17:71-79 [Persian]

15. Safdari R, Karami M, Moeini M. Causes of deductions applied by social security insurance in Kashan University of Medical Sciences hospitals. Journal of Health Information Management 2012 ; 9: 140-144 [Persian]

16. Safdari R, Sharifian $R$, Ghazi Saeedi $M$, Masoori N, Azad Manjir Z. The amount and causes deductions of bills in Tehran University of Medical Sciences Hospitals. Journal of Payavard Salamat 2011; 5: 61-70 [Persian]

17. Rostami Z, Nasiripour AA. Comparison of the Deductions of Insurance Bills in an EducationTreatment Center in Iran before and after Health Care Reform. Health Information Management 2019; 15: 281-287 [Persian]

18. Imani A, Doshmangir L. The Analysis of the Causes of Hospitalized Patients' Medical Records Deductions. Depiction of Health 2020;11:172189[Persian]

19. Yaqubi M, Javadi M, Jndqyan M, Rjalyan F, Farahabadi ME, Mofid M, Nazari M. Investigating the amount of deductions applied by the Social Security Organization to surgeries in selected teaching hospitals in Isfahan in the first half of 2008. Journal Hospital 2009; 8:33-38 [Persian]

20. Zarei E, Najafi M, Arabi S. Investigating Level and Reasons of Insurance Deductions of Hospitalization Bills in AL Zahra Academic and Medical Center of Isfahan in 2017 Evidence Based Health Policy. Management \& Economics 2020; 4: 32-39 [Persian]

21. Khalesi $\mathrm{N}$, Gohari $\mathrm{M}$, Vatankhah $\mathrm{S}$, Abbasimani Z. The Effect of Employee Training on Insurance Deduction Rate at Firoozgar Teaching Hospital 2008-2009. Journal of Health Administration 2011; 13: 19-26 [Persian]

22.Safdari R, Ghazi Saeedi M, Sheykhotayefe M, Jebraeily M, Farajolah SS, Maserat E, et al. The Study of Insurance Deductions from Point of Insurance Professionals in Educational Hospitals of Mashhad University of Medical Sciences. Journal of Payavard Salamat 2017; 11: 10-19 [Persian]

23. Askari R, Dehghan HR, Bahrami MA, Keshmiri F. Investigating the amount and causes of deductions in the bills of hospitalized patients Under the cover of social security insurance in educational hospitals Yazd University of Medical Sciences in the 
first half of 2008. Journal of Hospital 2009; 9: 24-28 [Persian]

24. Norooz Sarvestani E, Pour Mohammadi K, Kavoosi Z, Yousefi A. The amount and causes insurance deductions of Shohada-e Sarvestan hospital and ways to reduce it by using the techniques of problem-solving 2012. Journal Manage Med Inform Sci 2015; 2: 122-132 [Persian]

25. Bagheri H, Amiri M. Study of the causes of insurance organizations deductions from the therapy patients documents in one hospital in Iran. Healthcare Management 2013; 4: 17-24 [Persian]

26. Peabody JW, Luck J, Jain S, Bertenthal D, Glassman P. Assessing the accuracy of administrative date in health information system. Medicine care 2004; 42: 72-1066

27. Tabrizi J, Alidoost S, Mardi A, Farshikhorsand M, Rahmat M. Assessing the causes of dedicated revenues' fractions in health care centers and strategies to reduce them (A qualitative study). Journal of Hospital 2016; 15: 53-62 [Persian]

28. Krushat WM, Bhatia AJ. Estimating payment error for Medicare acute care inpatient services. Health Care Financ Review 2005; 26: 39-49
29. Howard WR. Respiratory care billing using a personal digital assistant. Respiratory Care 2004; 49: 1339-48

30. Helmons $P$, Grouls RJ, Roos A, Bindels A, Wessels-Basten S, Ackerman E, et al. Using a clinical decision support system to determine the quality of antimicrobial dosing in intensive care patients with renal insufficiency. Quality and Safety in Health Care 2010; 19: 6-22

31. Mokhtari S, Eskandari S \& Ayazi Z . Operators' performance evaluation on the hospital information system about the deductions of educational and medical Hajar hospital in 2012. Journal of Shahrekord University of Medical Sciences 2014; 15: 86-91 [Persian]

32. Wager KA, Lee FW, Glaser JP. Managing Health Care Information Systems: A Practical Approach for Health Care Executives. 1st Edition, John Wiley \& Sons: New Jersey, 2005

33. Abdelhak M, Grostick S, Hanken MA. Health information: Management of a Strategic Resource. $4^{\text {th }}$ Edition, Elsevier - Health Sciences: Philadelphia, 2014 